\title{
A Training Program For English Majors' Pragmatic Competence Based on Speech Act Theory
}

\author{
Shutao Zhou \\ College of Humanities and Social Sciences, Heilongjiang Bayi Agricultural University, Daqing, \\ China \\ Email:zhsht139@163.com
}

Keywords: speech act theory; college oral English; teaching; pragmatic competence

\begin{abstract}
Current oral English teaching model in college towards pronunciation correction and repeated practice dialogues has caused college students' pragmatic competence to lag behind their language proficiency. How to improve their communication skills and help them overcome the obstacle of "difficulty in speaking" has become a problem that college English teachers must take into account. Firstly, combining with practices of oral English teaching activities in colleges, this paper has analyzed the theoretical guiding significance of pragmatics on English teaching and explored how to cultivate students' pragmatic competence, so as to promote their English communicative competence. Secondly, from the perspective of speech act theory, the paper has discussed about its influences and inspirations on oral English teaching in colleges and thus learnt that: application of speech act theory in college oral English teaching is to strengthen students' recognition capability of indirect speech, contextual understandability, cognitive reasoning ability and appropriate communicative competence.
\end{abstract}

\section{Introduction}

Speech act theory (Speech Acts) serves as an important subject in pragmatic research. British philosopher Austen (J. Austin) first initiated specific research on it; American philosopher Searle (J. R. Searle) has improved the speech act theory, classified speech acts into five categories, proposed the indirect speech act theory and enriched research contents of pragmatics. This theory has deemed language use as acts and paved a new path to explore language use from an angle of act. It can be used for explaining unsolved linguistic phenomena such as syntax and truth-condition semantics and has been widely applied in researches upon varied disciplines, frontier branches of linguistics and related fields of discourse comprehension. This paper has mainly focused on its application in foreign language teaching, especially application and revelations of "illocutionary force" and indirect speech act theory in foreign language teaching.

\section{Speech Act Theory}

Generally speaking, college English teaching only pays attention to grammar, vocabulary and translation but undervalues culture and application of pragmatics in teaching. We must be clear that: when students enter colleges for study, they usually have grasped basic usage and rules of English grammar, and they urgently require improvements in broader and deeper English knowledge and English competence. In college English teaching, combination of language teaching with pragmatic teaching will be the optimal means to meet such requirements. As one of vital theories of pragmatics, indirect speech act theory boasts great importance to successive proceeding of communication. Analysis of indirect speech act theory is also of much significance to college oral English teaching, especially in cultivating students' pragmatic competence and communicative competence. The speech act theory was further developed by American linguist Searle (J.R.Searle) on the basis of analyzing Austen's speech act theory. Searle believes that language use is an intentional rules-regulated act, just like many other social activities of human beings (1969). Therefore, the process of language communication is actually composed of speech acts one after another, each of which can reflect intention of the speakers. Searle supposes that an indirect speech 
act will occur when an illocutionary act is indirectly expressed by another speech act. In daily communication, there often exists inconsistency between "literal meaning" used by people and "implied meaning" they want to express. During the process of communication, although we hope that both sides can speak frankly to achieve effective communication, speakers may express their own thoughts through indirect verbal means due to some specific purposes in some occasions and enable listeners to sense implied meanings rather than directly convey their ideas. To understand indirect speech act, we must first comprehend "literal meaning", from which the indirectly expressed "implied meaning" can be inferred.

In order to improve students' pragmatic competence and communicative competence, college English teachers should create more opportunities for students in oral English teaching and let them utilize acquired pragmatic knowledge in solving indirect speech problems and understanding implied meanings of speakers. Then we will discuss about inspirations of indirect speech act theory on college oral English teaching from four aspects.

\section{A Training Program for English Majors' Pragmatic Competence}

\section{Promote Students’ Recognition Capability for Indirect Speech}

First of all, teachers should properly teach some related knowledge of indirect speech act theory in due time so as to prepare students for theory and certain understanding for speakers' implied meanings. Secondly, in oral English teaching, college English teachers should actively provide students with language training in various forms and help them proficiently grasp functions of varied language forms in oral English practices. Thirdly, in dialogues, teachers should guide students to judge speakers' implications and thus grasp the real intention of speakers according to their tone, intonation, facial expressions and before-and-after discourse. For example, teachers can give a brief and natural dialogue to guide students to determine its related speech acts, predict speakers' relationship and understand speakers' implications. And then teachers should let students simulate the dialogue to express different language functions with identical utterances according to different judgments and understandings for speech acts, so as to cultivate students' sensitivity of the relationship between language forms and language functions.

Strengthen Teaching of Contextual Knowledge

In college oral English teaching, teachers should attach importance to the teaching of contextual knowledge. Context not only involves different social and cultural backgrounds of both communicative sides, but also refers to their standing, identity, relationship, age, gender, experience, cultural quality, etc. Context acts as an important factor in understanding indirect speech acts of both parties and the key to appropriate communication. Firstly, teachers should give students explanation of certain social and cultural background knowledge, in order to help them understand British and American cultural backgrounds and strengthen their cultural sensitivity. Secondly, in oral language training, teachers should also help students to correctly understand the relationship between language background and both communicative parties through analysis of a variety of scenes. Role playing is a good way to practice indirect speech acts. Teacher can provide students with context and information about both communicative parties, so as to enable students to figure out psychological activities of roles, experience the relationship between characters' mentality and utterances and play the role in terms of their own understanding. During such a process, students can actively understand and use indirect speech acts, and thus the teaching objective can be achieved.

Train Students’ Cognitive Reasoning Ability

In college oral English teaching, teachers should teach students to give full consideration to factors like social environments and mutual relationship of both communicative parties and thus adopt different communicative strategies in different language situations. Teachers should also strengthen training of students' language cognitive ability, which means not only letting students correctly understand speakers' intention but also promoting students' correct understanding and implementation of expressed "implied meanings". It requires teachers to provide a large number of conversational situations and language forms for students to practice. Students can gradually 
improve their reasoning ability for speakers' thoughts and ideas and effectively express their own implications only through constant practices.

Strengthen Students’ Ability for Appropriate Communication

Of course, our requirements for college students' oral English are not limited to understanding "implied meanings" of speakers, but students are also demanded to appropriately express their own ideas and opinions in English and help listeners to correctly understand and grasp their thoughts. Thus, in college English teaching, teachers should pay more attention to cultivating students' ability to appropriately use language: guide students to correctly judge the relationship between language background and both communicative parties; teach correct language forms to tell students how to appropriately use language and guide them to exercise in different situations, so as to achieve the teaching objectives.

\section{Specific Methods of Pragmatic Competence Training Based on Speech Act Theory}

Properly Handle the Relationship between Exam-Oriented Education and Real-Life English Communicative Competence

A good pragmatic competence is a necessary skill to achieve successful communication. It can be seen from research results upon the relationship between pragmatics and foreign language teaching that, learners' pragmatic competence won't spontaneously enhance along with promotion of their grammatical competence, and targeted measures shall be taken for education and training. In the light of present status of college English teaching, students' pragmatic competence training can be strengthened from the following aspects: integrate tasks of pragmatic competence training into the teaching plan; pay attention to both the teaching of general basic knowledge and pragmatic competence training; put strengthening of students' quality education in the first place instead of laying too much emphasis on requirements of TEM-4 and TEM-6.

Make Full Use of Foreign Teachers and Teaching Tools

Make full use of foreign teachers and intuitive teaching tools including English movies, TV, multimedia and network. Help students to fully understand different cultural backgrounds and local customs in different English-speaking countries and facilitate more intuitive impressions and more contacts with knowledge they cannot learn in class. Generally speaking, foreign language learners often involuntarily implant their mother tongue customs into foreign language use. Social pragmatic differences based on different geographical and cultural backgrounds will usually cause students to produce inappropriate language behaviors, which will then undermine the original context in discourse communication and thus lead to the failure of communication.

Transform the Roles of Teachers and Students, Develop Communicative and Interactive Class

Regional culture is the aggregate of material wealth and spiritual wealth of a nationality, while the corresponding language serves as the carrier and expression of its national culture. Only if pragmatic theory is introduced into English teaching, students can understand and grasp both pragmatic functions of language structure and practical meanings of relevant speech acts, so as to select appropriate language forms for expression according to their original intentions and effectively improve their practical application and understanding of language. Although development of pragmatics is still in the ascendant, its guiding significance to practice has attracted increasingly wider attention. For college English teachers, in order to well accomplish teaching tasks and actually improve students' English proficiency, they should apply pragmatic theory to every step in English teaching and regard it as an important approach to enhance students' English proficiency. Teachers should tell students language forms and illustrate pragmatic functions to them through repeatedly practicing related language forms in different situations, while letting students know the differences between Chinese and Western culture and social values in order to help them appropriately handle and speak in real-life communication. Only through actual combination of language competence and pragmatic competence, teaching activities of college English can truly tread the path towards quality education. 


\section{Conclusions}

The ultimate goal of college oral English teaching lies in enabling students to properly use the language for appropriate communication. Application of indirect speech act theory is to let students to emphasize the understanding of speakers' “implied meanings" in communication so as to infer speakers' true intentions. This requires college students to possess not only basic English knowledge but also certain pragmatic competence and cognitive reasoning ability. Application of the indirect speech act theory in college English teaching has exactly provided some new inspirations and methods for college oral English teaching and therefore become a must for students' pragmatic competence and communicative competence training.

\section{Acknowledgement}

Teaching research program of Heilongjiang Bayi Agricultural University (2014) " An empirical study on the cultivation of English Majors' pragmatic competence in agricultural universities based on speech act theory ".

\section{Reference}

[1] Kecskes I. How does pragmatic competence develop in bilinguals?[J]. International Journal of Multilingualism, 2015, 12(4):págs. 419-434.

[2] Suzuki T, Oda S, Tsuji K, et al. M102 An Undertaking of Utilizing English Speech Acts Corpora for the Cultivation of Pragmatic Competence(CHALLENGES FOR TERTIARY ENGLISH EDUCATION-JACET's Role in the next Fifty Years)[C]// The Japan Association of College English Teachers (JACET), 2011.

[3] Moskalagallaher B. The Speech Act of Complaint in English and in Russian and its Emergence in the Pragmatic Competence of Adult American Learners of Russian[J]. Dissertations \& Theses Gradworks, 2011, 25(4):402-412.

[4] Masouleh F A, Arjmandi M, Vahdany F. The Impact of Metapragmatic Instruction on Speech Act Awareness of Iranian Efl Learner[J]. Modern Journal of Language Teaching Methods, 2014, 4.

[5] Ghaemi H. The Impact of Task-Based Translator Training Program on the Development of Translation Competence[J]. New Voices in Translation Studies, 2014. 